\title{
E-Governance in Project Management: Impact and Risks of Implementation
}

\author{
Mounir El Khatib*, Laila Nakand, Saeed Almarzooqi, Aysha Almarzooqi \\ Hamdan Bin Mohammed Smart University, Dubai, United Arab Emirates \\ Email: ^drmunir.k@gmail.com, Laila-uae@hotmail.com, samalmarzooqi95@gmail.com, Aysha.almarzooqi89@icloud.com
}

How to cite this paper: El Khatib, M., Nakand, L., Almarzooqi, S., \& Almarzooqi, A. (2020). E-Governance in Project Management: Impact and Risks of Implementation. American Journal of Industrial and Business Management, 10, 1785-1811. https://doi.org/10.4236/ajibm.2020.1012111

Received: November 12, 2020

Accepted: December 20, 2020

Published: December 23, 2020

Copyright $\odot 2020$ by author(s) and Scientific Research Publishing Inc. This work is licensed under the Creative Commons Attribution International License (CC BY 4.0).

http://creativecommons.org/licenses/by/4.0/ (c) (i) Open Access

\begin{abstract}
This paper is about e-governance in project management. This topic is increasingly coming to focus as the project management methodologies are becoming more mature and the troubles in project management are not in processes, tools and techniques any more. The troubles in project management are in: how and who is taking the decision making and how to utilize project resources to the maximum possible level of effectiveness and efficiency. These two issues are the main concern of e-governance in project management. The aim is to understand the subject in a proper way, to focus on its impact, to highlight the risk of e-governance implementation and try to mitigate them and improve the processes of e-governance in organizations. This research uses a case study design in 3 organizations (Dubai Police, Road and Transport Authority (RTA), and the Dubai Health Authority (DHA)) by using qualitative research approach. The data is collected and analysed in a trial to address the gaps in this topic. The article concludes that combining the human mind and technological tools, such as AI and Blockchain and dashboard can add real value and drive positive change in project management governance. These tools allow project managers and stakeholders to make decisions and better governance of resources based on real-time data.
\end{abstract}

\section{Keywords}

E-Governance, Project Management, E-Governance Impact, E-Governance Risks and Implementation

\section{Introduction}

This research is titled "e-governance in project management". The objective is to uncover the impact of applying e-governance on project management and to reduce the related risks. Focus on the risks of implementing e-governance over 
project management is essential for ensuring an initiative's success.

Understanding the risks associated with e-governance is essential since it is one of the most critical components of project management in the digital world. E-governance controls all facets of business operations and oversight functions aligned with an organization's administrative structure and encompasses a project's life cycle. E-governance entails integrating technology in making and implementing decisions, ensuring proper leadership, establishing organizational plans, streamlining resource allocation and funding, establishing accountability, and measuring success (Department of Electronics \& Information Technology, 2012; Sebben Adami \& Verschoore, 2018). Specifically, e-governance uses information and communications technologies (ICTs) to deliver highly effective and efficient services to citizens and enterprises (E-Government Knowledgebase, 2020).

The implementation of artificial intelligence in the Dubai's Health sector has allowed Emirati to achieve substantial cost-savings and the delivery of high-quality services that denote the positive impacts of e-governance on project management (AlShamsi et al., 2020). Furthermore, the adoption of blockchain technology in Dubai and the wider UAE supports business innovation and sustainability despite creating value transfer risks (Petratos, Ljepava, \& Salman, 2020). Therefore, e-governance is vital in project management since it streamlines the critical processes required to successfully achieve an initiative's intended goals.

\section{Research Questions}

- What is the impact of e-governance on project management?

- What are the risks in implementing e-governance over the practice of project management?

\section{Literature Review}

\subsection{Description}

All the resources in the literature review contributed to this research's main objectives and aided in understanding and clarifying the path that the research should take.

\subsection{Project Governance}

Project governance is a vital management element that controls all aspects of business operations (Derakhshan, Turner, \& Mancini, 2019). Project governance has been defined in the Project Management Body of Knowledge (PMBOK) as an "oversight function that is aligned with the organization's governance model and encompasses the project life cycle" (Project Management Institute, 2013). Two popular definitions of governance are provided below:

Governance is a system of responsibilities, values, and processes that focus on achieving a particular project's goals by considering the interests of the organizations and their stakeholders (Nistor \& Beleiu, 2014). 
Governance is a high-level structure that defines the process and systems that control and manage an organization's projects and its strategic objectives Nielsen (2010).

From the definitions above, project governance could be considered as a set of management systems, rules, protocols, relationships, and structures that provide the framework within which decisions are made for project development and implementation to achieve an organization's business or strategic goals. To build a project governance structure and determine the governance level required to manage intended projects, many factors need to be considered. One factor to consider is organization size, which may involve several sponsors and stakeholders. Another factor is the job workload, which can lead to having several organization levels and can include building a specific program or portfolio (Naro \& Travaillé, 2011; Too \& Weaver, 2014).

The relationship between the governance of project management (GoPM), corporate governance, and project governance

Figure 1 shows Governance of project management (GoPM) as one dimension of project governance. GoPM can be described as focusing on areas related to project activities within corporate governance (ul Musawir, Abd-Karim, \& Mohd-Danuri, 2020). Corporate governance is a set of relationships between a company's management, its board, its shareholders, and other stakeholders. It also provides the structure through which the company's objectives are set, and the means of attaining those objectives and monitoring performance are determined (Grove \& Clouse, 2017). Corporate governance focuses on portfolio and program direction, project sponsorship, project and program management efficiency, and disclosure and reporting.

Understanding the relationship involving GoPM, corporate governance, and project governance will ensure a smooth and unobstructed exchange of information between the organization's board and key stakeholders (Zwikael \& Smyrk, 2019). Figure 2 represents the said relationship.

The base of GoPM can be summarized through a set of 13 governance principles developed with the aid of (Burak, Erdil, \& Altindag, 2017). These principles cope with the necessities of project management and are defined in the following list:

1) The governance of project management is the responsibility of the board.

2) The organization is responsible for differentiating among project and non-project-based activities.

3) The roles and obligations of project management governance are stated clearly.

4) Disciplined governance arrangements supported through suitable methods, resources, and controls are applied during the challenging life cycle. Every project has a sponsor.

5) There is a demonstrably coherent and supporting relationship between the general enterprise method and the project portfolio. 


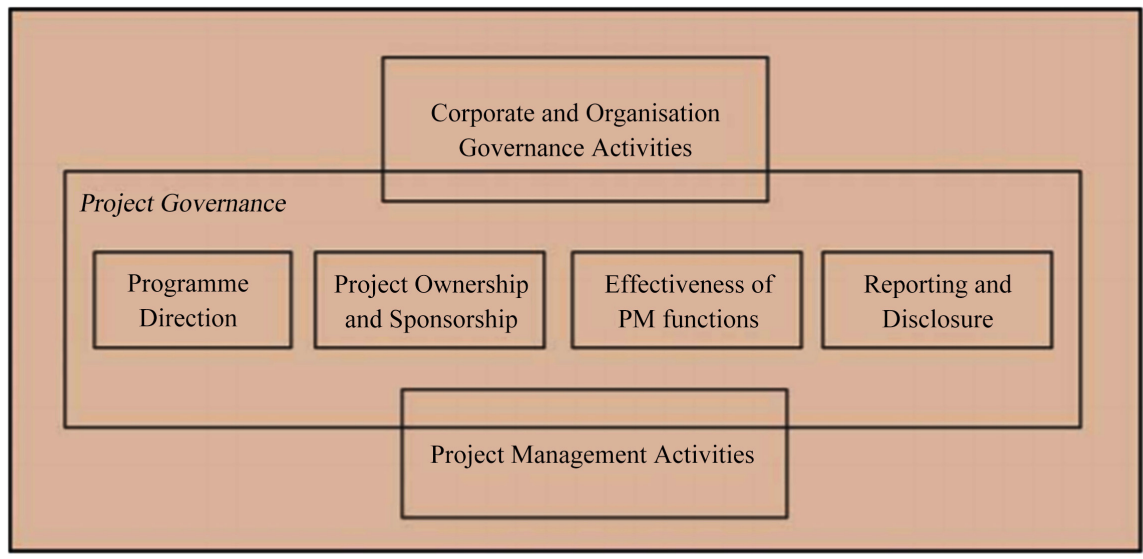

Figure 1. Project governance components (HM Treasury, 2007).

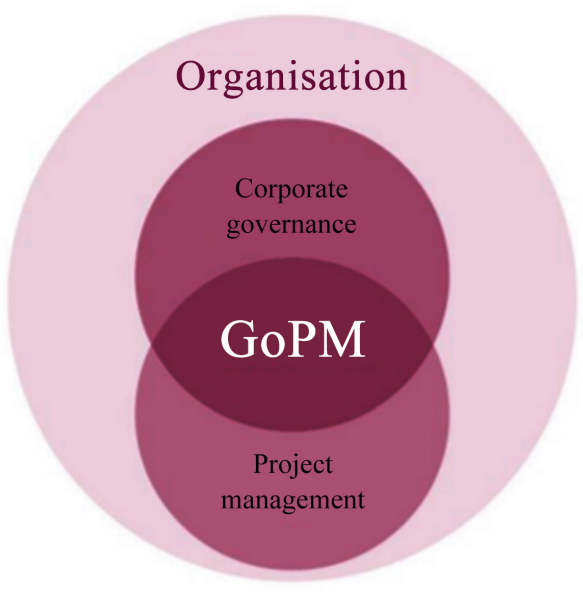

Figure 2. Governance of Project Management (GoPM) in context (Burak,, Erdil, \& Altindag, 2017).

6) All projects have an authorized plan containing authorization factors for which the business case, together with cost, advantages, and chance, is reviewed. Decisions made based on authorization factors are recorded and communicated.

7) Members of delegated authorization bodies have sufficient representation, competence, authority, and assets to permit them to make appropriate decisions.

8) Project enterprise instances are supported by applicable and realistic information that gives a reliable foundation for making authorization decisions.

9) The board, or its delegated agents, determine when independent scrutiny of management systems' initiatives or challenge is required and enforce such assurances accordingly.

10) There are defined criteria for reporting project status, escalating risks, and problems to the tiers required utilizing the company.

11) The company fosters a tradition of development and frank internal disclosure of Project Management (PM) information.

12) Project stakeholders are engaged at a level that is commensurate with their importance to the agency and in a manner that fosters trust. 
13) Projects are closed when they are no longer justified as part of the business enterprise's portfolio.

\subsection{E-Governance in Project Management}

The " $e$ " in e-governance stands for "electronic." The term refers to the use of ICTs to convert and support a governance system's techniques and structures. E-governance entails making and implementing decisions, maintaining proper leadership, streamlining organizational activities, securing resources and funding, establishing accountability, and measuring success (ul Musawir, Abd-Karim, \& Mohd-Danuri, 2020). The fulfillment of an e-governance project depends upon the holistic integration of the best governance practices within a business venture. E-governance is not merely the procurement of hardware and different networking equipment to create a technology-enabled project. Instead, it integrates the diverse fields of project management used to develop a comprehensive administration system.

In project management, implementing e-governance means using available technologies to develop matrices and performance indicators that enable the organization board, stakeholders, and sponsors to monitor and assist current and future projects. These indicators also allow for verification of a project's results (Kerzner, 2017). Figure 3 illustrates the described e-governance model and its various components.

The continuous evolution of technology has created a centralized control point in contemporary organizational hierarchies (Moutinho \& Kniess, 2012). Employing various business infrastructure and a solid sense of accountability and reliability, project governance has allowed value strategies to provide stability and sustainability to an organization (Ziemba, 2013). Subsequently, networking all processes into an easily governed centralized model facilitates smooth business operations.

\subsection{E-Governance and Project Risk Management}

Controlling risk is an essential part of project management. The primary concern of risk management is to resolve uncertainties related to the project completion process. Figure 4 shows the risk positions in a project's life cycle.

Comparing Figure 3 and Figure 4, it is clear that the e-governance model includes the tasks of risk management in its process. Risk concerning e-governance is mainly associated with arising issues with IT, which is, unfortunately, a common occurrence. According to Majchrzak et al. (2004), another set of risks can be labeled as hazards when overseeing a project virtually. These hazards can be mistrust, cliques, uninformed managers, and the allure of other exciting but unrelated work. Nonetheless, the resolution of risks and issues still depends on precise mitigation strategies executed quickly and efficiently (Preda, 2013; Sebben Adami \& Verschoore, 2018). Leadership must also ensure that all stakeholders are aware of the risk management process and agree to follow it. 


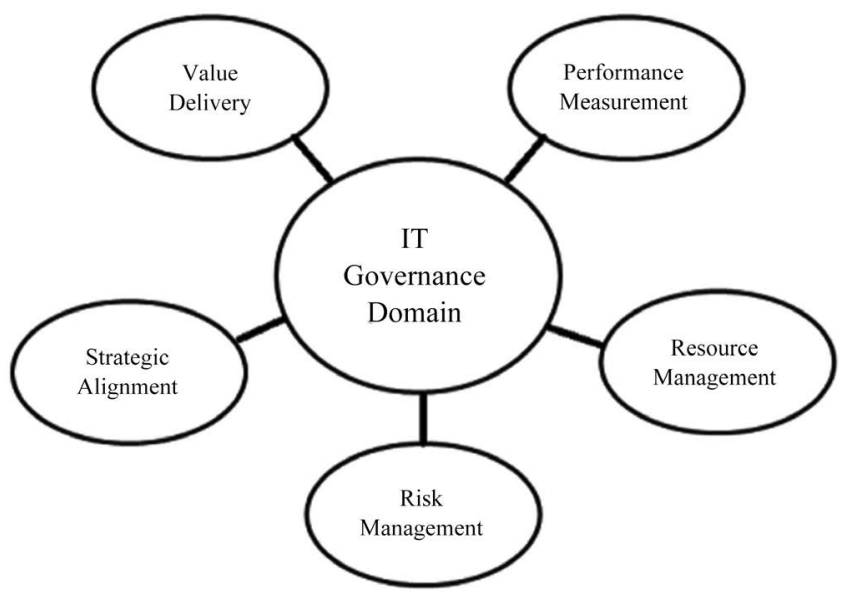

Figure 3. E-Governance model.

\begin{tabular}{|c|c|c|c|c|c|}
\hline $\begin{array}{l}\text { Project } \\
\text { Launch }\end{array}$ & $\begin{array}{l}\text { Risk } \\
\text { Analysis }\end{array}$ & $\begin{array}{l}\text { Risk } \\
\text { Manage }\end{array}$ & $>_{\text {Project }}^{\text {Main }}$ & $\begin{array}{l}\text { ject } \\
\text { estone }\end{array}$ & $>_{\text {Finish }}^{\text {Project }}$ \\
\hline $\begin{array}{l}\text { Identify scope } \\
\text { and goals }\end{array}$ & $\begin{array}{c}\text { Identify and } \\
\text { assess risks }\end{array}$ & $\begin{array}{c}\text { Create risk } \\
\text { strategy } \\
\text { collaborate with } \\
\text { risk-sharer } \\
\text { implement risk } \\
\text { policy }\end{array}$ & $\begin{array}{c}\text { Mainstream } \\
\text { operational tasks }\end{array}$ & Reassess risks & Project handover \\
\hline
\end{tabular}

Figure 4. Project life cycle and its relation to risk (Sebben Adami \& Verschoore, 2018).

\subsection{Project Management E-Governance Models and Tools}

Any system, when it begins, is influenced by its development models. E-governance models are purposely and specifically designed to guide the implementation and development of e-governance applications in a stage-wise manner. E-governance aims to improve governance processes and outcomes through new technology tools, such as AI, Blockchain, dashboards, and collaborative business intelligence (BI). They are used to monitor developmental projects. The tools are explained below:

\subsubsection{Artificial Intelligence}

AI is a tool used to monitor and guide projects through an online platform for project management teams and organizational decision-makers. The machine's inelegant learning process allows it to mimic human thinking, making it possible to learn from experience and adjust its performance tasks. This model aims to master the intricacies associated with traditional project management, such as time constraints and costs. Two key strategies, both of which apply artificial intelligence (AI) technologies, form this model: service design process and reusability capabilities. These components induce lower maintenance costs and higher efficiency while also avoiding considerable independent design costs for different sectors. They also incorporate an extension for external agencies to liaise with governance, particularly for consulates and other diplomatic scenarios (Prasad, 2018). AI and its use applications span across different sectors, such as health, technology, water, traffic, education, space, transport, and renewable en- 
ergy.

In e-governance, the application of $\mathrm{AI}$ improves query response mechanisms and may mitigate waste of time among board members, shareholders, and CEOs managing a project. For example, the incorporation of AI in e-governance can automate routine pricing tasks, reduce paperwork, improve query response time, and save project managers' standard time to specialize in other development issues (Mohanty, n.d.).

Despite the benefits of AI in e-governance, there are some risks related to it. For example, a lack of knowledge in operating the adopted ICTs can make managing projects difficult. If data has been incorrectly entered, it may undermine the quality of the decisions made by a project management team.

AI affects project management in specific ways. In big data and business analytics, gathering data using simple approaches could be time-consuming and incapable of capturing accurate data. Consequently, such risks may undermine the efficiency of implementing e-governance in project management. When given information that does not fit into structured project cognitive technologies, like tongue processing (NLP), e-governance systems integrated in project management use advanced algorithms to research text to derive insights and sentiment from unstructured data. AI also reduces the threat of fraud, especially when it involves a budget, because the computer analytics can detect errors and omissions, which makes it more accurate and secure. It is an assistive technology to suggest strategies and probabilities of outcomes.

The wide acceptance and use of technology systems in contemporary organizational settings is inevitable, as Hans (2016) claims that "Together, humans and computers are going to be ready to do things that were just impossible previously." Merging humans with computers is often also achieved using AI. To reduce risks, merging like policies, controls, and procedures enhance an organization's compliance with regulators and regulatory changes (Institute of Risk Management, 2019).

Figure 5 is of ABB's process control and shows a visual control graphic interface. The graphic interface displays process information in its situational context and is an automation software solution for the mining and cement industries. The system's goal is to reach the best plant productivity, safety, and, therefore, best operator efficiency (ZKG Cement, 2019). Similarly, such an extent of automation could be applied in government and business organizations to allow project managers to coordinate activities efficiently.

\subsubsection{Blockchain}

Blockchain is another tool used to record all transactions and digital events in the internet world. No user can manipulate the information recorded, so there would be no worry about being cheated among strangers. The concept is concerned with financial transactions, and it extends to transactions of smart contracts, which run without any human intervention. The blockchain model aims at the aspects of security, automation, and decentralization of digital assets. In 


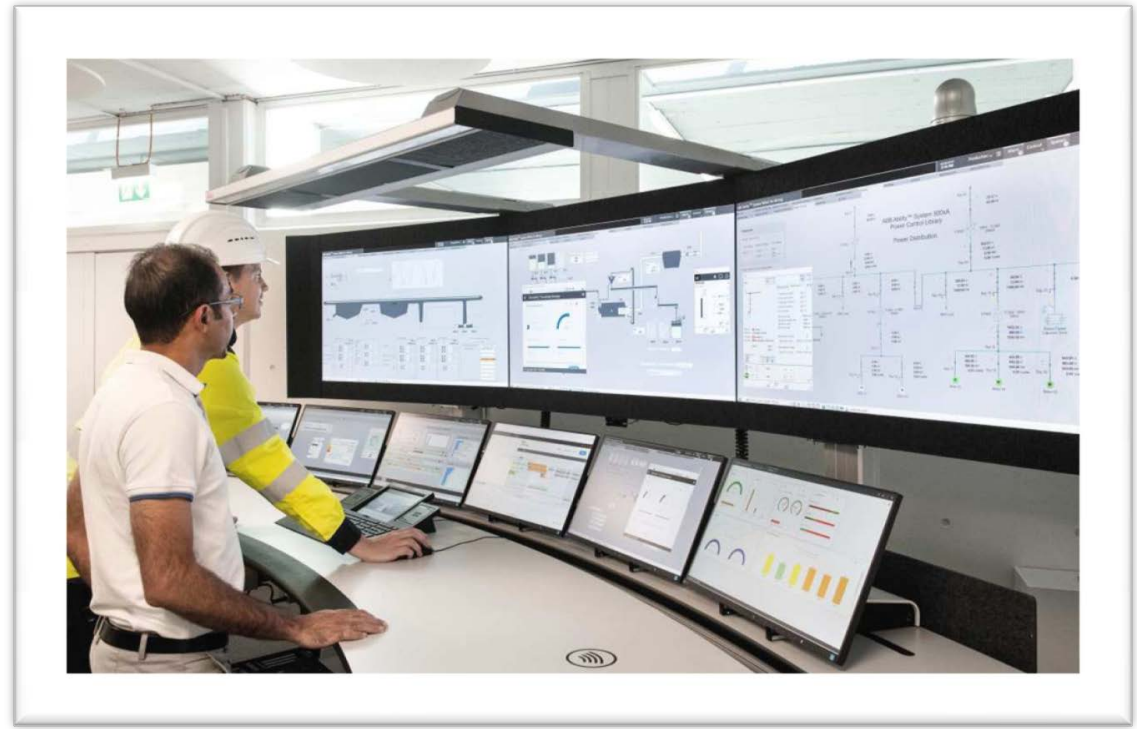

Figure 5. Example of a project manager in control.

e-governance, the application of blockchain technology focuses on regulating the processes of creating and managing digital records, exchanging digital assets, verifying and reinforcing acceptable performance, building reputation systems, executing smart contracts, and maintaining an unalterable source of truth (Qi et al., 2017).

The correct e-governance model for a platform depends on several factors found in the following list (Van der Weerd, 2017):

- strategy and mission-criticality

- policy and decision making and risk-sharing

- participant roles, responsibilities, and representation

- node management

- type and variety of international regulatory jurisdictions

- desired permission level of features

- cost of ownership, including financing and cost charging

- Supervisory bodies and assurance.

Risks to take into consideration to e-governance technology are a lack of scalability and continuity, which affects the project reliant on Blockchain. Other risks involve cryptographic essential management functions, and likewise algorithms, as improper management of cryptographic key-pairs could result in unauthorized access to an organization's information management system.

Considering the risks mentioned above primarily complicates blockchain transactions because of the absence of a trusted third party or a central authority. Where current IT environments of organizations can typically be thought of as centralized silos (operated and managed by one party) that are logically separated from one another, Blockchain-powered IT environments dissolve these boundaries as organizations transact on the identical system (Van der Weerd, 2017). 
Norris (2013) provides an example of how Blockchain can implement e-governance. The author explains, if a company had scheduled its construction contractor to send people on a particular date and those people were subsequently sent too late or too early, everyone with access to the related ledger could verify if the contractor made an error or not (Norris, 2013). In this light, the execution of e-commerce using blockchain technologies allows project managers in areas such as construction to monitor critical activities and identify problems that hinder the attainment of pre-determined objectives. Project managers can also use the ledger's knowledge to research business operations and seek new efficiencies and savings of time and money (Norris, 2013).

\subsubsection{Dashboard}

A dashboard is an interface that displays complex data to users in real-time. It is a platform that displays and presents a mix of KPIs, such as metrics, in one central location to enhance a project's performance and make an organization more intelligent (Durcevic, 2020). The creation of dashboards became technologically feasible with advances in data warehousing (a database that can be queried) and online analytical processing (OLAP) (selective analysis of the data based on purpose to provide status reports and decision support) (Vila, Estevez, \& Fillottrani, 2018). Dashboards are an essential tool for decision-makers.

Dashboards promise smooth data-driven decision making in the e-governance environment. They can inform decisions for cutting costs, provide new insight into citizens' concerns, and allow smarter policy and operational choices. Dashboards help relay important project information without unnecessary details that may be confusing or irrelevant to stakeholders. The technology allows projects to be more efficient by presenting continuous data at a glance. Dashboards benefit project team members, managers, and stakeholders because they all have access to the project's progress, health, and projections. In summation, the benefits of dashboards using dashboards include greater convenience, increased efficiency, improved accuracy, better communication, and persuasive evidence.

The risk associated with implementing a dashboard in projects is in the complexity of mining all required data in one system. The data mining intricacies associated with dashboards make an accessible query interface available only in standardized reports. Consequently, a dashboard might not answer all the questions arising from enterprise executives and stakeholders, resulting in decision-making delays.

Figure 6 for example shows that the Dubai Statistics Center has developed a dashboard as a new service to facilitate its e-governance processes. After receiving customer feedback to include relevant statistics from government and private sectors, as well as individuals, the Dubai Statistics Center adopted a dashboard system to enhance the data administration and decision-making aspects of project management. This dashboard delivers the latest economic and social indicators in Dubai through a live dashboard linked to the centralized statistical repository, which assists in studies and research for decision making. 


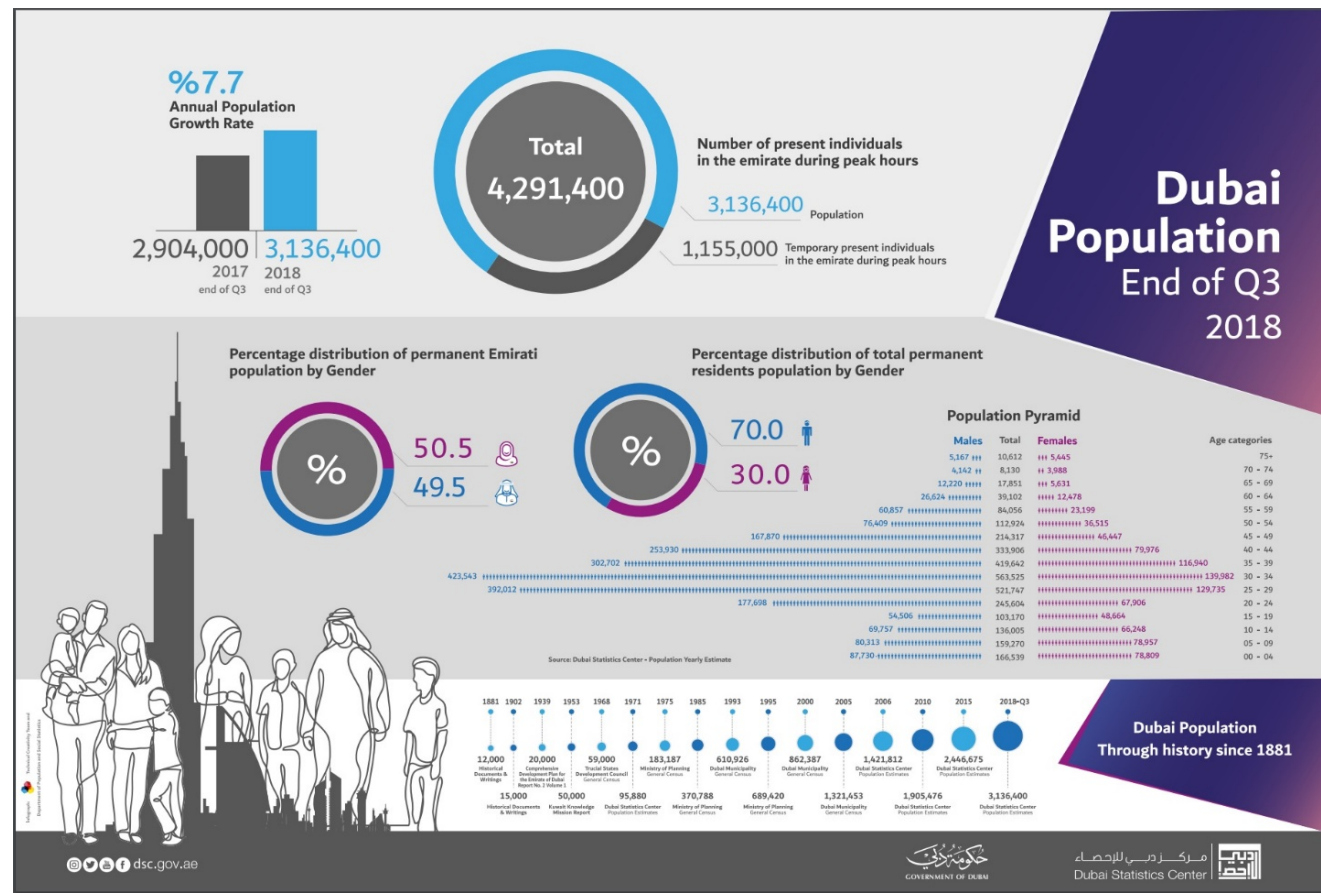

Figure 6. A sample of population and vital statistics from the Dubai Statistics Center's website (Government of Dubai, 2019).

\subsection{Critical Success Factors}

Perhaps the most straightforward approach for tackling the organizational aspects of projects is through critical success factors (CSFs). In project management, CSFs represent the vital requirements for the achievement of an initiative's goal or mission. CSFs are developed to agree on the project goals, create clearly defined plans, manage the scope efficiently, streamline communication, and ensure management support.

All participants share the same documentation of the project CSFs, which can only be updated through consensus. Furthermore, changing one transaction record would require the alteration of all subsequent records and, thus, require the entire network's collusion. Therefore, data regarding a project's CSFs are typically more accurate, consistent, and transparent. The data is also available to all participants who have permission to access it.

Moreover, dashboards, among other e-governance technologies, allow project managers to identify the goals and benefits that determine if a project, program, or portfolio can produce the desired results. E-governance applications minimize unforeseen project risks and increase opportunities to create value and ensure the sustainability of a venture (Iannacci et al., 2019).

Detailed project management is one aspect of CSF that leads to developing an algorithm for organizing information. The information can then be analysed more accurately using the dashboard system in project management. Dashboards are crucial in project management since they streamline change processes, information dissemination, and communication transparency (Nadgowda, 2015). 


\section{Methodology Design}

\subsection{Research Design}

This research uses a case study design. The organizations focused on are the Dubai Police, Road and Transport Authority (RTA), and the Dubai Health Authority (DHA). The research topic is the impact of e-governance in project management and identifying the risks of implementing e-governance practices over project management. By using qualitative research and analysing the collected data, this study seeks to address the gaps in this topic area to improve the processes of e-governance in organizations.

Case study research design analyses specific events or conditions and their relationships. A case study analysis is relevant to the topic of e-governance in project management since it allows researchers to observe the phenomena in situations where it occurs, especially in diverse and exploratory contexts (Kompella, 2020). The case study design is relevant to the topic being investigated since it allows researchers to analyse a single or multiple contemporary real-life bounded system over time. Notably, the topic under study is relatively new and, thus, adopting a qualitative case study method facilitates the collection of data from various sources and analysis to identify major themes relating to the impact and risks associated with the application of e-governance in project management. Furthermore, Rahi (2017) claims that case studies are useful when the researcher has no control over the events under inquiry. In the context of this investigation, the researcher has no control over the impacts and risks related to e-governance in project management, which makes the case study design relevant to the topic.

The research design of longitudinal research was not used because it must be repeated over a specific period, such as three months. This approach was not appropriate due to the period that is specified for this course. Neither was the comparative design applicable to this research, as this specific research design calls for comparing two or more case studies. Finding case studies related to the topic being investigated could be difficult since the integration of e-commerce in project management is a relatively new concept. The third research design is not featured in the experimental design. According to McLeod (2007), this design consists of two subjects: the experimental and control groups. The researcher controls the variables during the study for a single group. The present research does not control any factors in the study. This research obtains data about the chosen topic through qualitative research. The fourth and last research design that did not apply to this study is the cross-sectional design. According to Cherry (2018), this research design targets different groups with different variables. Nonetheless, the groups share similar features to observe and describe data from the groups without manipulation. As mentioned previously, this research has no interest in comparing two or more groups.

\subsection{Qualitative Approach}

The qualitative approach was selected for this research because of its usefulness 
in gaining insight into the participants' reasons and different opinions regarding a specific topic. Phone and WhatsApp interviews would be administered by the research team to collect data. This knowledge will help us better understand the problem and reach the hypothesis made for this research (Sauro, 2015). Moreover, the qualitative approach allows the researcher to explore specific topics in-depth and better explain the impact of e-governance in project management.

In addition to the qualitative approach, the quantitative method was valuable for the research as well. The approach aided the researcher to limit the methods in which a participant could answer a question. Therefore, the findings remained within the research boundaries. The quantitative method also prevents the participants from providing biased feedback since it is based on statistical data. Finally, the quantitative approach added strength to the research since the data were analyzed using statistical analysis, which is objective and rational (McLeod, 2017).

The qualitative researcher's preoccupation is seeing through the heart of the participants by understanding their meanings and terminologies. It is also the researcher's role to maintain auditory communication as well. Another concern for the researcher is giving a detailed description of what is happening during an interview and the purpose of the interview. Also, a qualitative approach allows the researcher to transform the participants' different concepts and theories into valuable data for analysis and justification of the research hypothesis.

The qualitative data would be represented in an array of ways. First, for more straightforward analysis and interpretation, the interviews' data will be represented in numerical data. For the causality, data will be described as represented from the measurements. If replication of this study ever occurs, the results will be the same since personal biases have not influenced the findings. Finally, the researcher used proper sampling techniques to ensure that the findings can be generalized.

Concerning the objective and subjective aspects of the qualitative research, the researcher followed a subjective manner. During data collection, the researcher worked closely with the participant and showed feelings and empathy with them in order for the participants to open up and speak about the matter at hand. Qualitative research allowed the researcher to gain more insight into the topic and understand the participants' theories.

\subsection{Reliability and Validity}

Research must be reliable and valid. The plan for ensuring the reliability and validity of the research is as follows.

\subsubsection{Reliability}

To ensure stability, the measures of the questions were stable and reliable to avoid confusion. If the participant ever goes through the interview questions again, the same answers will be granted, or at least results with a high correlation.

To ensure internal reliability, the researcher attempted to explain the ques- 
tions to the participants during the interview by phone or WhatsApp.

\subsubsection{Validity}

The researcher evaluated the data-collection tools to ensure their face validity based on the researcher's own opinion. The instruments used to gather data were aligned with the intended purpose of the research and the research questions. To ensure construct validity, the researcher reviewed that the instruments used would generate results that can be generalized when the study was later done. Also, a concurrent validity test took place, as the results generated from the analysis were compared with the data gained from the organizations in the literature review regarding the impact of e-governance in project management and the risks of implementing e-governance over project management.

Furthermore, predictive validity will occur, as the measures will predict some effects that the subject of research should have. Moreover, convergent validity was used with the instruments to ensure that they would generate related data. Finally, to ensure content validity, the instruments will cover a wide range of meanings included in the concepts the research is trying to test.

\subsubsection{Concepts and Variables}

The researcher developed two primary questions to be answered after conducting the interviews and analysing the data gathered. Those two research questions are the following:

- What is the impact of e-governance in project management?

- What are the risks of implementing e-governance over project management? The main research concepts would be extracted from the case data demonstrating the interrelationships surrounding the phenomenon under investigation. Each concept identified requires more than one variable to be measurable because multiple variables lead to better distinction among individuals. In addition, multiple variables capture multiple dimensions of a concept. This enables the researcher to deeply understand the topic and formulate questions relevant to the acquired data, consequently achieving the goal of the study. This is unlikely to happen if one variable is used since it might only capture a portion of the concept.

\subsubsection{Sampling}

The research used samples instead of the entire population because the latter approach is costly and consumes much time. Therefore, using samples is convenient for the case study design. The research contains both probability sampling and non-probability sampling. The probability sampling approach will entail stratified random sampling from different departments. The non-probability sampling strategy would employ judgmental sampling. The researcher will choose specific people from the strata based on their experience and awareness of the processes and the topic at hand.

This research's sampling error is expected from the non-response case when a participant has not fully answered a question. The researcher will then have to 
look for another participant that would give correct and full answers. The participants must be aware of the topic and be experienced enough with it so that the given data is accurate and allows the research to prove or reject the hypothesis.

The type of probability sampling used in this research is stratified random sampling. Since specific people from specific departments and sections were chosen based on their awareness of the topic and its processes, they will give the best answers and data regarding the research matter. Judgmental sampling, also known as purposive sampling, was used as a non-probability sampling type for this research. The reason was that the researcher could choose particular participants that were suitable for the research and obtain a high probability of receiving adequate data.

\subsubsection{Data Collection}

The qualitative data was collected using interviews. The gathering of data prioritizes ethical research protocols by ensuring no harm to the respondents and avoiding invasion of privacy. The purpose of the data was explained verbally to respondents. Respondents participated in the interview of their own will. Appendix A shows both the qualitative interview questions and the generated responses. The data collected was used in the analysis section below.

\subsubsection{Coding}

The following table contains the words and phrases used in the qualitative data coding. To view the original data coding, please refer to Appendix B.

\begin{tabular}{llllll}
\hline Control project & $\begin{array}{l}\text { Responsibility, } \\
\text { accountability }\end{array}$ & $\begin{array}{l}\text { Policies, } \\
\text { strategies }\end{array}$ & Procedures & $\begin{array}{l}\text { Provide decision Real-time } \\
\text { making }\end{array}$ & $\begin{array}{l}\text { Ensure real risk } \\
\text { governance to action } \\
\text { Improve }\end{array}$ \\
\hline $\begin{array}{l}\text { Real-time monitor } \\
\text { and analysis }\end{array}$ & $\begin{array}{l}\text { Positive change } \\
\text { effectiveness risk } \\
\text { communication }\end{array}$ & e-management & $\begin{array}{l}\text { Help provide } \\
\text { assurance }\end{array}$ & $\begin{array}{l}\text { Technology will bring a } \\
\text { higher level of effectiveness }\end{array}$ & Achieve the result \\
\hline
\end{tabular}

\section{Analysis \\ Qualitative Data Analysis}

There are several implications for e-governance on the management of a project, as identified and mentioned during the interview. Establishing a culture of e-governance among the individuals and teams implementing a project is suggested whenever an organization wants to apply ICTs to project management. Organizations can implement modern technologies, such as Blockchain and AI, successfully by assembling project teams that constitute members with the required skills, knowledge, and experience to lead the implementation of ICTs in projects. However, there are several risks in implementing e-governance over project management, such as security breaches of systems. Since privacy is a contentious ethical issue in the modern business world, project managers apply- 
ing e-governance should ensure that they uphold the required standards for information management security.

Some procedures can be followed to help achieve a positive impact on e-governance. Identifying risks to e-governance for project management is beneficial and ensures the project goal's achievement at the specified time and cost.

According to the previous articles, a governance department contributes to the improvement and development of a project. It works to link and integrate processes and steps that facilitate the process of supporting decision-makers, and thus, contributes to achieving the organization's strategic goals.

Some risks and challenges that prevent e-governance from achieving a project's goal are the financial budget and the commitment of the project team. Organizations may fail to make budgetary allocations for their e-governance activities since most managers are sceptical about integrating technology systems in project management. Additionally, if the project team is uninterested and uncooperative in implementing e-governance, its projects' success would be undermined. Furthermore, insufficient knowledge of e-governance and sudden changes to the project may also disrupt the team's commitment expected to use technology in implementing their tasks. These challenges pose a risk to project management.

Risk management is part of project management, and e-governance is also concerned with risk. E-governance reduces expected project risks by adjusting the project phases' actual time and simplifying and tariffing project costs. If e-governance is implemented in project management, it will reduce project risks.

Through the qualitative interview, the tools of artificial intelligence, such as Blockchain, can contribute to the work's organization. The challenges that will be faced through Blockchain's use are that the scope of the project cannot be expanded during its use, which works to adhere to the project. Therefore, the lack of flexibility when using Blockchain in project management is a significant challenge that undermines the full adoption of e-governance.

Some methods are used as tools to grant the government initiatives' achievement in the General Directorate of Residency and Foreigners Affairs (GDRFA) for risks and governance teams. Those methods are internal excellence awards, monetary rewards, workshops, regular meetings, quarterly evaluation, friendly meetings, professional and moral support, establishing a government management guide and services, G2 B, G2G projects.

An effective control environment can be designed when organizations become part of digital ecosystems. Digitalization and technologies bring higher levels of effectiveness, such as the support of the higher management.

\section{Limitations}

There were several limitations during this research that were all overcome. The first limitation was time. The time to do such research is too short since the duration lasted for only two months. Nonetheless, the researcher managed to submit all assignments on time. The second limitation occurred after the qualitative 
interview. Due to the Covid-19 pandemic, the qualitative interview was conducted through WhatsApp. This led all workers in the government sector to be isolated at home. Another limitation of this research is that it was not pilot tested in an organization. However, it will be tested to know the results and prove its reliability and validity.

\section{Recommendations and Conclusions}

\subsection{Recommendations}

1) The government needs to develop legislation and regulations to ensure a systematic and transparent workflow for e-governance activities.

2) In addition to policies and procedures that cover security issues and cyber-attacks, security measures shall be included in the development process of an e-government system design and configuration of its principles.

3) Continued review and feedback from technological development worldwide to be up to date, which will help in facilitating the work of e-governance. For example, e-governance needs to up to date from the front-end (As customer side) and back-end (as an appliance in data centers) to avoid cyber-attacks and ensure the system will work continuously.

\subsection{Conclusion}

This paper details the critical success factors necessary for e-governance's seamless operations across the UAE. This study states that more employees agree with the benefits associated with e-governance frameworks. Many clients and employees have been deterred from adopting an e-governance framework due to the cost of implementation. They were also worried about disruption during their adoption of e-governance within project management. With time, e-governance, mainly via AI and Blockchain, will become a key priority for numerous organizations within the UAE because it provides multiple benefits across business, government, and individuals. We believe that $\mathrm{AI}$ is undoubtedly changing how projects are achieved and delivered with the lowest risk possible. However, there is something that AI will not be able to have: a human mind. This makes the presence of project managers necessary. Soft skills such as leadership, people management, communication, empathy, emotional intelligence, and project management passion will always be essential. Thus, managers, surveyors, accountants, engineers, and human engagements are not replaceable. Combining the human mind and technological tools, such as AI and Blockchain, can add real value and drive positive change in project management. The research also focused on dashboards as a tool that helps to understand changing business conditions visually. This particular tool allows project managers and stakeholders in e-governance to make decisions based on real-time data. Hopefully, this will become the tool of a new wave of project decision-making where time zones and time delays will no longer be significant factors in resolving project issues, making decisions, and collaborating to achieve a new project success level. 


\section{Conflicts of Interest}

The authors declare no conflicts of interest regarding the publication of this paper.

\section{References}

AlShamsi, M., Salloum, S. A., Alshurideh, M., \& Abdallah, S. (2020). Artificial Intelligence and Blockchain for Transparency in Governance. In Artificial Intelligence for Sustainable Development: Theory, Practice and Future Applications (pp. 219-230). Cham: Springer. https://doi.org/10.1007/978-3-030-51920-9 11

Burak, E., Erdil, O., \& Altindag, E. (2017). Effect of Corporate Governance Principles on Business Performance. Australian Journal of Business and Management Research, 5, 8-21.

Cherry, K. (2018). Cross-Sectional Research Method: How Does It Work? Advantages and Challenges.

https://www.verywellmind.com/what-is-a-cross-sectional-study-2794978

Department of Electronics \& Information Technology (2012). E-Governance Project Life-Cycle Reading Supplement Handbook. New Delhi: National Institute for Smart Government.

Derakhshan, R., Turner, R., \& Mancini, M. (2019). Project Governance and Stakeholders: A Literature Review. International Journal of Project Management, 37, 98-116. https://doi.org/10.1016/j.ijproman.2018.10.007

Durcevic, S. (2020). How to Create A Project Management Dashboard-Examples \& Templates. [Blog] The Datapine Blog.

https://www.datapine.com/blog/project-management-dashboards-examples-and-templ ates

E-Government Knowledgebase (2020). E-Government. https://publicadministration.un.org/egovkb/en-us/about/unegovdd-framework

Government of Dubai (2019). Population and Vital Statistics. https://www.dsc.gov.ae/en-us/Dubai-Infographs/Pages/Dubai-Infographs.aspx

Grove, H., \& Clouse, M. (2017). Corporate Governance Principles and Sustainability. Corporate Governance and Sustainability Review, 1, 13-19. https://doi.org/10.22495/cgsrv1i2p2

Hans, S. (2016). Why Artificial Intelligence Is a Game Changer for Risk Management. https://www2.deloitte.com/content/dam/Deloitte/us/Documents/audit/us-ai-risk-powe rs-performance.pdf

HM Treasury (2007). Project Governance: A Guidance Note for Public Sector Projects. https://assets.publishing.service.gov.uk/government/uploads/system/uploads/attachme nt data/file/225314/01 ppp projectgovernanceguidance231107.pdf

Iannacci, F., Seepma, A. P., De Blok, C., \& Resca, A. (2019). Reappraising Maturity Models in e-Government Research: The Trajectory-Turning Point Theory. The Journal of Strategic Information Systems, 28, 310-329. https://doi.org/10.1016/j.jsis.2019.02.001

Institute of Risk Management (2019). Artificial Intelligence and Risk Management. https://enterpriseriskmag.com/artificial-intelligence-risk-management

Kerzner, H. (2017). Project Management Metrics, KPIs, and Dashboards: A Guide to Measuring and Monitoring Project Performance. Hoboken, NJ: John Wiley \& Sons. https://doi.org/10.1002/9781119427599

Kompella, L. (2020). Socio-Technical Transitions and Organizational Responses: Insights 
from e-Governance Case Studies. Journal of Global Information Technology Management, 23, 89-111. https://doi.org/10.1080/1097198X.2020.1752082

Majchrzak, A. et al. (2004). Can Absence Make a Team Grow Stronger? Harvard Business Review, 82, 131-137.

McLeod, S. (2007). Experimental Design. https://www.simplypsychology.org/experimental-designs.html

McLeod, S. (2017). Qualitative vs. Quantitative. https://www.simplypsychology.org/qualitative-quantitative.html

Mohanty, P. K. (n.d.). Using E-Tools for Good Governance and Administrative Reforms.

Moutinho, J. A., \& Kniess, C. T. (2012). Contributions of a Project Management Office in a Laboratory of R\&D of a Public University. Revista De Gestão e Projetos, 3, 282. https://doi.org/10.5585/gep.v3i2.116

Nadgowda, M. (2015). Critical Success Factors in E-Governance Projects. https://www.slideshare.net/mukundnadgowda/critical-success-factors-in-e-governance -projects

Naro, G., \& Travaillé, D. (2011). The Role of the Balanced Scorecard in the Formulation and Control of Strategic Processes. Journal of Applied Accounting Research, 12, 212-233. https://doi.org/10.1108/09675421111187674

Nielsen, B. B. (2010). Strategic Fit, Contractual, and Procedural Governance in Alliances. Journal of Business Research, 63, 682-689. https://doi.org/10.1016/j.jbusres.2009.05.001

Nistor, R., \& Beleiu, I. (2014). Approaches Regarding the Dimensions of Project Governance. Proceedings of the 8th International Management Conference, Bucharest, 6-7 November, 2014, 2.

Norris, T. (2013). How Blockchain Will Change Project Management.

Petratos, P. N., Ljepava, N., \& Salman, A. (2020). Blockchain Technology, Sustainability and Business: A Literature Review and the Case of Dubai and UAE. In Sustainable Development and Social Responsibility-Volume 1 (pp. 87-93). Cham: Springer. https://doi.org/10.1007/978-3-030-32922-8 7

Prasad, R. S. (2018). Applying AI in Governance Will Let India Leapfrog Many Developmental, Infrastructural Constraints.

https://economictimes.indiatimes.com/tech/software/applying-ai-in-governance-will-le t-india-leapfrog-many-developmental-infrastructural-constraints/articleshow/6402050 $\underline{6 . \mathrm{cms}}$

Preda, C. (2013). Implementing a Risk Management Standard. Journal of Defense Resources Management, 4, 111-120.

Project Management Institute (2013). A Guide to the Project Management Body of Knowledge. Newtown Square, PA: Project Management Institute. https://doi.org/10.1002/pmj.21345

Qi, R., Feng, C., Liu, Z., \& Mrad, N. (2017). Blockchain-Powered Internet of Things, e-Governance and e-Democracy. In E-Democracy for Smart Cities (pp. 509-520). Singapore: Springer. https://doi.org/10.1007/978-981-10-4035-1 17

Rahi, S. (2017). Research Design and Methods: A Systematic Review of Research Paradigms, Sampling Issues and Instruments Development. International Journal of Economics \& Management Sciences, 6, 1-5.

Sauro, J. (2015). 5 Reasons to Perform a Qualitative Study. https://www.studocu.com/en-us/document/florida-state-university/special-topics-in-re ligion/lecture-notes/measuring-u-5-types-of-qualitative-methods/2768371/view

Sebben Adami, J. R., \& Verschoore, J. R. (2018). Implications of Network Relations for 
the Governance of Complex Projects. Project Management Journal, 49, 71-88. https://doi.org/10.1177/875697281804900205

Too, E., \& Weaver, P. (2014). The Management of Project Management: A Conceptual Framework for Project Governance. International Journal of Project Management, 32, 1382-1394. https://doi.org/10.1016/j.ijproman.2013.07.006

ul Musawir, A., Abd-Karim, S. B., \& Mohd-Danuri, M. S. (2020). Project Governance and Its Role in Enabling Organizational Strategy Implementation: A Systematic Literature Review. International Journal of Project Management, 38, 1-16.

https://doi.org/10.1016/j.ijproman.2019.09.007

Van der Weerd, S. (2017). How Will Blockchain Impact an Information Risk Management Approach?

https://www.compact.nl/articles/how-will-blockchain-impact-an-information-risk-ma nagement-approach

Vila, R. A., Estevez, E., \& Fillottrani, P. R. (2018). The Design and Use of Dashboards for Driving Decision-Making in the Public Sector. Proceedings of the 11th International Conference on Theory and Practice of Electronic Governance, Galway, 4-6 April 2018, 382-388. https://doi.org/10.1145/3209415.3209467

Ziemba, E. (2013). The Holistic and Systems Approach to the Sustainable Information Society. The Journal of Computer Information Systems, 54, 106-116. https://doi.org/10.1080/08874417.2013.11645676

ZKG Cement (2019). ABB Reinvents Process Control with New Generation Human-Machine Interfaces.

https://www.zkg.de/en/artikel/zkg ABB reinvents process control with new generat ion human-machine interfaces 3458683.html

Zwikael, O., \& Smyrk, J. R. (2019). Project Management. Cham: Springer. https://doi.org/10.1007/978-3-030-03174-9 


\section{Appendix}

\section{Appendix A}

\section{Question research with answers:}

1) What is the key principle of governance for project management in government?

Answer: The following points list those principles:

* The governance of project management is the responsibility of the board.

* The organization is responsible for differentiates among projects and non-project-based activities.

* Project management governance's roles and obligations are stated clearly.

4 Disciplined governance arrangements, supported by way of suitable methods, resources, and controls, are applied during the challenging life cycle. Every project has a sponsor.

* There is a demonstrably coherent and supporting relationship among the general enterprise method and the project portfolio.

* All projects have an authorized plan containing authorization factors at which the business case, together with cost, advantages, and chance, is reviewed. Decisions made at authorization factors are recorded and communicated.

* Members of delegated authorization bodies have sufficient representation, competence, authority, and assets to permit them to make appropriate decisions.

* Project enterprise instances are supported by using applicable and realistic information that gives a reliable foundation for making authorization decisions.

* The board or its delegated agents determine when independent scrutiny of initiatives or challenge management systems is required and enforce such assurance accordingly.

* There are defined criteria for reporting project status and escalating risks and problems to the tiers required by means of the company.

* The company fosters a tradition of development and of frank internal disclosure of PM information.

* Project stakeholders are engaged at a level that is commensurate with their importance to the agency and in a manner that fosters trust.

+ Projects are closed when they are now not justified as part of the business enterprise's portfolio.

2) How can the project governance develop project management?

* There is big relationship between project governance and project management.

- This relationship will ensure smooth and unobstructed exchange of information between the organization board and the related stakeholders.

+ Governance of project management (GoPM) is one of the project governances' dimensions. 
And it can be understood as the practice of focusing on areas related to project activity within the corporate governance.

* Corporate governance, in turn, means a set of relationships between a company's management, its board, its shareholders, and other stakeholders.

* It also provides the structure through which the objectives of the company are set, and the means of attaining those objectives and monitoring performance are determined.

3) How does e-governance enhance project management success in your organization?

* The project governance system allowed value strategies to provide stability and sustainability to the organization, thus employing various business infrastructure with a solid sense of accountability and reliability.

As a result, networking all processes into an easily governed centralized model enabled business smooth operations.

E-Governance entails making and implementing decisions, proper leadership, putting in place organizational arrangements, ensuring resources and funding, establishing accountability, and measuring success. The fulfillment of an e-Governance venture depends upon the improvement of the venture in an integrated and holistic manner.

E-Governance is an integration of diverse fields of PM to develop a complete management system rather than a technology-enabled project.

* In project management, part of implementing e-Governance means; using available technologies to develop matrices and performance indicators to enable the organization board, stakeholders, and sponsors to monitor and assist the current and future projects. Also, project indicators will allow having verification for projects' results.

4) What is the relationship between project risk management and e-governance in project management?

* Project risk management is an essential part of project management, and its primary concern is dealing with uncertainties related to the project process.

* The risk relation to the e-Governance mainly associated with the IT arising issues which is, unfortunately, commonly occurs.

* There is another type of risks that can be labeled as hazards when overlooking the project virtually.

o And, how can e-governance reduce the risks on project?

* The resolution of risks and issues depends on precise mitigation strategies executed in a timely and efficient manner. Leadership must also ensure that all stakeholders are aware of this process and agree to follow it.

5) How can the artificial intelligence effect on e-governance? And why? And what are its risks?

E governance is to improve governance processes and outcomes with a view to improving throw a new technology and tools such as AI. They are used to monitor developmental projects. 
AI is one of the tools that is helping to monitor and guide projects through an online platform for project management's teams and organizational decision makers.

\& AI is aimed at beating the intricacies associated with traditional project management such as time constraints and costs.

AI reduces the danger of fraud especially when it involves a budget wise because the computers analytic can detect and be more accurate and robust. It's an assistive technology to assist suggest strategies and probabilities of outcomes.

* Certain merging is often done also in AI to scale back risks like merging policies, controls, procedures and with the regulators and regulatory changes to enhance their organizations' compliance.

o And why?

* In e Governance AI improving Query response mechanism for board members, shareholders, CEO's which may reduce time waste and price automating routine tasks reduces paperwork and improves query-response time and saves the standard time of state officials to specialize in other development issues.

0 and What are its risks?

* There are some risks related to AI in such of lack of knowledge which makes it difficult to manage projects or if data has been mesenteries which make the choice makers difficult to gauge.

However, AI has effects project management in e governance during a certain way, among those huge data and business analytic the normal methods incapable of catching and time-consuming to process data volume as its finding is known and therefore the unknown risks.

6) How will the blockchain contribute to achieving e-governance? Reducing the risks of e-governance? How can this be guaranteed? And what do you think about blockchain as part of e-governance?

- In e Governance, the application will consider the way of regulation going to be and modified including creating and managing digital records, exchanging digital assets, verifying and reinforcing acceptable performance, building reputation systems and executing smart contracts as well as maintaining an unalterable source of truth.

* The correct e governance model for a platform depends on a certain factor:

- strategy and mission-criticality.

- policy/decision-making and risk sharing.

- participant roles, responsibilities and representation.

- node management.

- type and variety of international regulatory jurisdictions.

- desired permission level of features.

- cost of ownership, incl. financing and cost charging.

- Supervisory bodies and assurance. 


\section{o Reducing the risks of e-governance?}

* Risks related to such technology are, lack of scalability and continuity which affects the project counting on block chain. Moreover, cryptographic key management function likewise algorithm, public key improper management of cryptographic key-pairs might end in unauthorized access of the system.

o How can this be guaranteed?

* These risks primarily relate to the absence of a trusted third party or a central authority. Where current IT environments of organizations can typically be thought of as centralized silos (operated and managed by one party) that are logically separated from one another, block chain powered IT environments dissolve these boundaries as organizations transact on the identical system.

o And what do you think about blockchain as part of e-governance?

- As an example of how this tool is implementing a e governance suppose if you had scheduled your construction contractor to send people on a particular date and that they send their people too late or too early, everyone on the ledger can verify if the subcontractor made an error or not. You can also use the knowledge within the ledger to research business operations to seek out new efficiencies and savings of your time and money.

7) What are the sources of governmental initiatives to implement project management in e governance?

\& strategy and mission-criticality.

* policy/decision-making.

8) What are the major challenges that face the proper implementation of project management in e governance?

* AI has effects projects management in e governance during a certain way, among those huge data and business analytic the normal methods incapable of catching and time-consuming to process data volume as its finding is known and therefore the unknown risks.

9) Will risk managers bring their own human biases to artificial intelligence?

10) How can an effective control environment be designed when organizations become part of digital ecosystems?

Digitalization and technologies will bring higher levels of effectiveness.

\section{Appendix B}

\section{First Interview}

Name or organization: DP.

1) What is the key principle of governance for project management in government?

- Accountability and responsibility.

- The principles are: There should be formally agreed governance arrangements. There should be a single point of decision making for the project. There should be a clear and unambiguous allocation of authority for re-presenting the project in contacts with owners, stakeholders and third parties. 
2) How can the project governance develop project management?

- Ensuring that everyone is accountable and responsible will ensure commitment and achievement of results.

- It makes it more efficient, and this relationship will ensure smooth and unobstructed exchange of information between the organization board and the related stakeholders.

3) How does e-governance enhance project management success in your organization?

- Faster response and better clarity.

- It empowers real time monitoring and deep dive analytics and networking all processes into an easily governed centralized model enabled business smooth operations.

4) What is the relationship between project risk management and e-governance in project management? And, how can e-governance reduce the risks on project?

- Applying governance will reduce risks.

- They go hand in hand, E governance assures effective Risk management and real time monitoring, and also risks that can be labeled as hazards when overlooking the project virtually.

5) How can the artificial intelligence effect on e-governance? And why? And what are its risks?

- Faster response and better decision making.

- It gives it more real time empowerment.

- AI reduces the danger of fraud especially when it involves a budget wise because the computers analytic can detect and be more accurate and robust. It's an assistive technology to assist suggest strategies and probabilities of outcomes.

- AI has effects projects management in e governance during a certain way.

6) How will the blockchain contribute to achieving e-governance? Reducing the risks of e-governance? How can this be guaranteed? And what do you think about blockchain as part as e-governance?

- Blockchain as a ledger will help provide assurances.

- In e Governance the application will consider the way of regulation going to be.

- Risks related to such technology which are lack of scalability and continuity which affects the project counting on block chain.

- These risks primarily relate to the absence of a trusted third party or a central authority.

7) What are the sources of governmental initiatives to implement project management in e governance?

- DGEP criteria.

- E services, G2 B, G2G projects.

- Strategy. 
8) What are the major challenges that face the proper implementation of project management in e governance?

- Teamwork.

- Culture, mindset, top management buy in.

9) Will risk managers bring their own human biases to artificial intelligence?

- Yes, this could be a risk area.

10) How can an effective control environment be designed when organizations become part of digital ecosystems?

- Full integration and new type of training.

- Ecosystems are aligned with read/ write capabilities, Single Source of Truth, and are generally real time, so they empower effective performance.

\section{Second interview}

Name of organization: DHA.

Question research: e-governance.

11) What is the key principle of governance for project management in government?

Integrated planning is most important to ensure projects are well planned following certain guidelines and also all projects have an authorized plan containing authorization factors at which the business case, together with cost, advantages, and chance, is reviewed. Decisions made at authorization factors are recorded and communicated.

12) How can the project governance develop project management?

* Governance will help project management to ensure its alignment with the organization objectives thorough continuous monitoring however it can be understood as the practice of focusing on areas related to project activity within the corporate governance.

13) How does e-governance enhance project management success in your organization?

* In my organization PMO office is the one that will do the governance but it's still under process. However, their main goal will be to focus on all organization projects to make sure they are following the right project management disciplines, \& also E-Governance is an integration of diverse fields of PM to develop a complete management system rather than a technology-enabled project.

14) What is the relationship between project risk management and e-governance in project management? And, how can e-governance reduce the risks on project?

Risk management is important in all projects type because they have to keep an eye on all risks that can happen, while governance is to maintain overall projects including risks. The risk relation to the e-Governance mainly associated with the IT arising issues which is, unfortunately, commonly occurs.

By the resolution of risks and issues depends on precise mitigation strategies executed in a timely and efficient manner. 
15) How can the artificial intelligence effect on e-governance? And why? And what are its risks?

AI will help improve the way projects are governed as it will provide advanced tools to monitor projects.

* AI is one of the tools that are helping to monitor and guide projects through an online platform for projects management's teams and organizational decision makers. AI shortens query-response time which enables state officials to focus on other issues that need further development. However, there are some risks related to AI.

16) How will the blockchain contribute to achieving e-governance? Reducing the risks of e-governance? How can this be guaranteed? And what do you think about blockchain as part as e-governance?

Blockchain will be a useful part in governance and management but organization should also consider different risks while using it like security risk.

* IT environments dissolve these boundaries as organizations transact on the identical system.

Implementing a e governance suppose if you had scheduled your construction contractor to send people on a particular date.

17) What are the sources of governmental initiatives to implement project management in e governance?

- Thorough strategies and also policy.

18) What are the major challenges that face the proper implementation of project management in e governance?

To change the culture is a challenge.

19) Will risk managers bring their own human biases to artificial intelligence?

Maybe, there is big challenge and risks.

20) How can an effective control environment be designed when organizations become part of digital ecosystems?

Through advanced tools and procedures.

Third interview

Name of organization: RTA.

Question research: e-governance.

1) What is the key principle of governance for project management in government?

Governance refers to the set of policies, regulations, functions, processes, procedures and responsibilities that define the establishment, management and control of projects, programs and portfolios.

2) How can the project governance develop project management?

Project governance is the management framework within which project decisions are made. Therefore, the role of project governance is to provide a decision-making framework that is logical, robust and repeatable to govern an organization's capital investments. 
3) How does e-governance enhance project management success in your organization?

It empowers real-time and/or near real time governance to action.

4) What is the relationship between project risk management and e-governance in project management? And, how can e-governance reduce the risks on project?

Risk and governance are intertwined, and governance can assure real Risk Management effectiveness.

5) How can the artificial intelligence effect on e-governance? And why? And what are its risks?

AI carries its own risks, and need to be part of the governance framework, AI also empowers governance to be data driven, real-time analytics, real-time monitoring and control and more.

6) How will the blockchain contribute to achieving e-governance? Reducing the risks of e-governance? How can this be guaranteed? And what do you think about blockchain as part as e-governance?

Blockchain is a technology that is ledger based, so every block in the chain is well governed by time stamp and verified by many, so it is impossible to change.

7) What are the sources of governmental initiatives to implement project management in e governance?

E-government incorporates four key elements that, when combined, create a unified process: e-services, e-commerce, e-democracy and e-management.

8) What are the major challenges that face the proper implementation of project management in e governance?

Executive buy in, mind set and organizational culture.

9) Will risk managers bring their own human biases to artificial intelligence?

Yes, we are human, this will need to be dealt with as a risk.

10) How can an effective control environment be designed when organizations become part of digital ecosystems?

Digitization and Digitalization and technologies will bring higher levels of effectiveness if they are properly leveraged. 